\title{
Para Que Serve a Literatura?
}

\author{
MARio BARENGHI* \\ Tradução: Cláudia Tavares Alves**
}

A

meu ver, questionar-se sobre "o que é literatura?" ou "o que é um texto literário?", como Giovanni Bottiroli ${ }^{1}$ fez, não é a maneira mais adequada de encarar o problema do ensino de literatura na universidade, muito menos na escola. A questão a ser colocada não deveria ser ontológica, mas sim funcional. É preciso interrogar-se sobre o escopo da literatura, o que quer que seja: sobre sua razão de ser. Para que serve? Para que nós a usamos? Com quais motivações? E tendo em vista que objetivos e vantagens? Tendo que dar uma definição bastante genérica, tomo emprestada a fórmula que o linguista israelense Daniel Dor usa para definir a linguagem².

A literatura é uma técnica de "instrução da imaginação" que não serve simplesmente para "comunicar", mas para fazer viver experiências simuladas. Por meio de uma prática de simulação socialmente compartilhada (portanto, diferente da fantasia individual), o leitor tem a possibilidade de ampliar o conjunto de sua experiência existencial: de clareá-la e enriquecê-la, articulá-la e ampliá-la, adquirindo assim novos instrumentos para enfrentar os desafios da vida real.

Também poderíamos formular essa ideia em termos moralmente mais exigentes. A finalidade das obras literárias deveria ser nos ajudar a viver. Servem para viver: assim soa o título de um ensaio inteligente de Bruno Falcetto (subtítulo: Rumo a uma educa-

1 Em "La letteratura se iniziassimo davvero a studiarla", disponível em: <http://www.doppiozero.com/ materiali/la-letteratura-se-iniziassimo-davvero-studiarla>; acesso em 24 de dezembro de 2019.

2 DOR, Daniel. The Instruction of Imagination: Language as a Social Communication Technology. Oxford: Oxford University Press, 2015.

\footnotetext{
* Mario Barenghi é crítico literário e professor de literatura italiana contemporânea na Universidade Bicocca de Milão. O artigo “A cosa serve la letteratura?” foi publicado em 13 de junho de 2017, em Doppiozero, e está disponível em: <https://www.doppiozero.com/materiali/ cosa-serve-la-letteratura>; acesso em 24 de dezembro de 2019. Todas as notas são da tradutora. **Doutoranda em Teoria e História Literária pela Universidade Estadual de Campinas. Bolsista FAPESP (2016/07884-0) / clautalves@gmail.com.
}

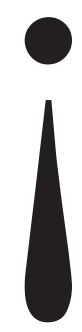


ção para o uso da literatura) $)^{3}$. Para viver, ou para sobreviver, ou para nos fazer viver melhor, como escreveu Tzvetan Todorov em um livro de 2007, A literatura em perigo ${ }^{4}$. Como reiterou Antoine Compagnon, no mesmo ano, em sua aula inaugural ao Collège de France, Literatura para quê $?^{5}$, a literatura serve para nos tornar mais felizes. Ou menos infelizes. E para nos tornar melhores: mais sábios, mais sagazes, mais sensíveis, mais previdentes (aqui, Compagnon cita uma célebre passagem do ensaio "O miolo do Leão", de Calvino ${ }^{6}$ ); em geral, mais preparados para interpretar o mundo que nos circunda, o mundo humano in primis. Como consequência, melhor inseridos no ambiente que nos é próprio: mais hábeis em compreender nossos semelhantes, suas ações e suas atitudes, assim como as dinâmicas das relações que nos ligam a eles; mais preparados para compreender o sentido e o peso das palavras, nossas e dos outros.

Mas atenção: a literatura não produz esses efeitos de maneira automática. Pelo contrário, pode acontecer que ela não os produza minimamente. Não apenas e nem tanto porque, além da grande literatura, exista também a literatura ruim, mas sobretudo porque (o caso dos textos sagrados ensina) não existe livro bom de que não se possa fazer mau uso, do mesmo jeito que não existe utensílio (ferramenta, equipamento, competência ou conhecimento) de que os "estúpidos" e os "bandidos" não possam se valer, para usar duas categorias de Cipolla, em Allegro ma non troppo ${ }^{7}$. Podemos nos consolar, talvez, ao pensar que o contrário também é verdadeiro: de um livro medíocre pode se fazer um uso positivo. Fato é que o ensino de literatura deveria seguir esse objetivo: aumentar as probabilidades de que, na experiência literária dos alunos, os efeitos considerados profícuos, desejáveis, esperados prevaleçam aos considerados negativos.

Ora, a experiência literária se sustenta sobre dois procedimentos fundamentais: a personificação e o envolvimento. A princípio, o primeiro parece dizer respeito à esfera da produção do texto (o autor) e o segundo à esfera da recepção (o leitor). Na realidade, ambos são sempre chamados para entrar em jogo, já que é de fato por meio da personificação que o autor visa a envolver o leitor, ao passo que o leitor pode reconhecer intenções pessoais ou formas de personalização do discurso para além das intenções conscientes do produtor do texto. Mas esses são detalhes teóricos; o ponto principal é outro. Sobre o que fala a literatura? Sobre tudo, obviamente. A literatura pode representar qualquer coisa. Não apenas qualquer aspecto da vida real, mas qualquer realidade

3 "Servono per vivere: verso un'educazione all'uso della letteratura" integra o volume La didattica della letteratura nella scuola delle competenze. Pisa: Edizioni ETS, 2014.

$4 \quad$ A literatura em perigo. Tradução de Caio Meira. Rio de Janeiro: DIFEL, 2012.

5 Literatura para quê?. Tradução de Laura Taddei Brandini. Belo Horizonte: Editora da UFMG, 2009.

6 O ensaio "O miolo do leão" integra o volume Assunto encerrado: discursos sobre literatura e sociedade. Tradução de Roberta Barni. São Paulo: Companhia das Letras, 2009.

$7 \quad$ Allegro ma non troppo con Le leggi fondamentali della stupidità umana. Bolonha: Il Mulino, 1988. 
hipotética, fictícia, imaginária, contrafactual. Seu traço diferencial é que ela faz isso simulando pessoas. Pode tratar de figuras humanas, em sentido próprio, talvez completo, como ocorre nas representações teatrais ou nos romances, nos quais se fala justamente sobre "personagens", dramatis personae, ou na lírica, que encena explicitamente um "eu". Mas pode tratar também, mais sutilmente, de um arranjo do discurso suficientemente personalizado para evocar uma presença humana, como acontece também nos poemas mais abstratos ou didascálicos, nas descrições mais impassíveis, no ensaísmo. A linha divisória é sempre uma imputação do concreto: qualquer coisa que o texto diga, qualquer que seja o tema que proponha ou o argumento que desenvolva, ele é incorporado, encarnado (embodied), isto é, personificado.

A personificação pode seguir os caminhos mais diversos: oferecer-se com clareza documental, com nome, sobrenome, data de nascimento, ascendência familiar e por aí vai; ou evocar uma silhueta humana de maneira mais fugidia, e por isso mesmo mais sugestiva; ou ainda antropomorfizar entidades (forças ou criaturas) não humanas; ou apenas disseminar o texto com pegadas e traços, encrespando a superfície verbal com inflexões bastante acentuadas e reconhecíveis, a fim de estimular a referência a uma personalidade particular.

"Particular" é uma palavra-chave. Tomemos o enunciado tertium non datur. A partir de um conceito abstrato como esse, a literatura oferece exemplificações que sempre contêm algo a menos (motivo pelo qual não podemos abrir mão da lógica) e algo a mais (motivo pelo qual vale a pena ler narrativas). Pular ou não pular do navio, o dilema de Lord Jim; ceder à intimação dos mercenários ou não, a alternativa que Dom Abbondio descarta a priori sem compreender o que isso significa. Estamos no reino do particular concreto. Mas estamos também onde, em uma obra literária, os enunciados gerais se encontram; é o conjunto das circunstâncias particulares a produzir uma pressão osmótica na experiência do leitor. Por outro lado, se somos permeáveis a casos particulares é porque a vida vem, justamente, ao nosso encontro como uma sequência (ou um conjunto) de circunstâncias particulares.

Em todo caso, para o processo acontecer - para que a literatura funcione como tal -, o leitor, por sua vez, deve se sentir envolvido. Deve se interessar: isto é, deve literalmente fingir estar no meio (inter + esse). Deve se sentir se não arrebatado, ao menos atraído, isto é, solicitado, envolvido. O mecanismo é aquele da máxima proverbial de Horácio: mutato nomine, de te fabula narratur (Sat., I, 1, 69-70). Não existe experiência literária sem algum grau de participação. Seria errado, aliás, reduzir a ideia de participação à dimensão emotiva e sentimental, em particular ao impulso da identificação empática com os personagens romanescos. Uma forma de empatia sempre existe, mas também pode despertar a atitude problemática ou humorística ou racional que ganha corpo no discurso. Quem fala - quem quer que seja - a encarna, a incorpora. A linha divisória é sempre um tipo específico de corporeidade, a materialidade (ainda que seja virtual) de uma presença pessoal.

Vejamos então a questão do ensino mais de perto. É possível ensinar literatura? Aqui Bottiroli tem razão: "o que um professor de Letras pode fazer é criar condições para que seja possível uma experiência estética. Não pode impô-la, mas pode favorecê-la". 
E tem também razão ao sustentar que o professor não deve criar obstáculos. Eu diria, mais drasticamente, que deveria evitar causar danos: primum non nocere, de acordo com a preciosa advertência da Escola Médica Salernitana. Concordo menos, porém, quando Bottiroli coloca em oposição a atenção dada aos "textos" e a atenção dada aos "contextos", denunciando as consequências nefastas do "contextualismo" ("o contextualismo mata a literatura"). Com certeza, tratar um texto da mesma forma que um mero documento sobre alguma outra coisa, reduzindo-o a um suporte para indagações de ordem histórica, psicológica, social, “cultural”, significa sufocá-lo. Porém danos não menos graves foram produzidos - principalmente na escola, pelo que me consta - pelo abuso de noções e grades elaboradas pela teoria literária. Não se lê um romance para aprender o que significam as palavras "prolepse" e "analepse".

O que está matando a literatura, na minha opinião, é a indiferença para com os leitores. Eu não diferenciaria tanto "artefato" e "objeto virtual" (termos com os quais Bottiroli se refere ao "conjunto das interpretações possíveis"), mas sim "texto" e "obra", onde obra é o texto concretamente reativado pela leitura: executado - no sentido musical da palavra - por um leitor ou por uma comunidade de leitores. Franco Brioschi cita várias vezes - por exemplo, no prefácio a Gli immediati dintorni: primi e secondi, de Vittorio Sereni ${ }^{8}$ - o epigrama citado por Possídio no final de sua biografia de Santo Agostinho. A intenção do poeta latino era celebrar a função eternizadora da poesia, mas esses dois versos servem muito bem para representar a reativação do texto por obra do leitor: Vivere post obitum vatem vis nosse, viator? Quod legis, ecce loquor; vox tua nempe mea est ("Queres saber, viandante, se o poeta vive após a morte? Tu lês, e então eu digo: a tua voz é a minha”). A poesia revive, ou antes, vive literalmente na leitura. Ora, se a literatura conta enquanto simulação de experiências, não se pode descuidar do fato de que cada experiência é contextual. Dito de outra maneira, quem ensina, ensina sempre a alguém; e cada um dos sujeitos implicados traz consigo um conjunto de contextos dos quais não se pode abrir mão (ainda que, obviamente, se deva evitar com cuidado as derivas impressionistas).

Demonstrar que um texto literário permite muitas interpretações possíveis, ou que foi lido em diversas chaves, é instrutivo, mas não altera as coisas, pelo menos não enquanto não tenha sido ativada uma forma de identificação, de participação - isto é, enquanto a indiferença do destinatário não tenha sido abalada. O ponto crucial é que, a partir do texto, deveria ocorrer, aqui e agora, alguma coisa de importante para quem o está lendo. Obviamente, é impossível dizer a priori o quê (no fundo, essa é a beleza da literatura).

Seguindo esse ponto de vista, estou totalmente de acordo com a insistência de Nadia Fusini sobre o papel do leitor (Ler com o ouvido $)^{9}$. O centro da experiência literária é a leitura, então é muito justa a solicitação de que para o objetivo da "educação à

8 Gli immediati dintorni: primi e secondi. Milão: Il Saggiatore, 2013.

9 Disponível em: <https://www.doppiozero.com/materiali/leggere-con-lorecchio>; acesso em 24 de dezembro de 2019. 
leitura" se envolvam "a escola, a universidade, a crítica e a estética" Todavia, tenho uma reserva complementar sobre a avaliação da leitura "de escape". Oferecer a possibilidade de escapar de um presente frustrante, opressor ou doloroso não é trivial; e, para além do alívio momentâneo, as experiências estéticas "de escape" podem produzir até efeitos colaterais mais consistentes e menos efêmeros do que suspeitamos. Por outro lado, quem lê com o objetivo "sério" de entender como anda o mundo pode muito bem cometer erros, incorrer em mal entendidos. Muito pior do que os leitores ingênuos ou descompromissados são os leitores superficiais, presunçosos, capazes apenas de encontrar confirmações para convicções já adquiridas.

Uma imagem de bom leitor é encontrada nas palavras do romancista Silas Flannery, o alter ego de Calvino em Se um viajante numa noite de inverno ${ }^{10}$ : "Dos leitores, espero que eles leiam nos meus livros algo que eu não sabia, mas posso esperar isso apenas daqueles que esperam ler algo que eles não sabiam".

Concluo. Talvez pudesse se dar como certa uma familiaridade generalizada com a experiência literária na universidade de outros tempos. Os estudantes, pelo menos nas Faculdades de Letras, nutriam um interesse consolidado pela literatura: se não por todos os autores do nosso cânone histórico-literário, decerto por muitos clássicos da modernidade. Não sei se essas circunstâncias se reproduzem hoje em alguma ilha privilegiada do arquipélago acadêmico. Pessoalmente, ensino em cursos de graduação nos quais a literatura não é uma prioridade no pensamento dos estudantes, então não posso deixar de me colocar o problema de como despertar-lhes interesse, no sentido de interesse como indicado acima. Esforço-me para fazer com que as leituras que proponho interajam com suas consciências - obviamente, nos modos próprios da literatura. Sei com certeza que não consigo com todos, nem - receio - com a maior parte; mas faço votos de conseguir ao menos com alguns. De todos tento, entretanto, exigir que percebam a densidade do texto literário, a riqueza do uso das palavras, a complexidade da construção do discurso, a importância dos temas tratados. Tudo isso não será suficiente para que ocorra uma experiência estética verdadeira; mas se nesse ínterim eu conseguir não suscitar um desgosto excessivo, uma reação de repulsa pela literatura em geral, poderá valer, quem sabe, como pressuposto ou plataforma para experiências futuras. Não é muito, mas é melhor do que nada. 